\title{
User-Centric Approach to Specifying Technical Attributes of Drug Delivery Devices: Empirical Study of Autoinjector-Cap Removal Forces
}

This article was published in the following Dove Press journal: Patient Preference and Adherence

\author{
Andreas Schneider ${ }^{\prime}$ \\ Philipp Richard' \\ Philippe Mueller' \\ Christoph Jordi' \\ Mary Yovanoff ${ }^{2}$ \\ Jakob Lange (iD ${ }^{\prime}$ \\ 'Ypsomed AG, Burgdorf, Switzerland; \\ ${ }^{2}$ Design Science, Philadelphia, PA, USA
}

\begin{abstract}
Purpose: The subcutaneous delivery of biologics using pre-filled autoinjector devices continues to attract broad scholarly interests. However, research still lacks a detailed understanding of user perceptions as the basis for specifying the clinically relevant technical attributes of a device, such as the cap-removal force. Therefore, this article studies the ability of users to remove the autoinjector cap, as well as the effects of the cap-removal force and user characteristics on the perceived ease of decapping.

Patients and Methods: Forty-two participants among patients, caregivers, and healthcare professionals removed the protective cap using non-functional devices with different target cap-removal forces between $25 \mathrm{~N}$ and $55 \mathrm{~N}$. Data were collected on the ability of the users to effectively decap the device and their perceived ease of decapping. Linear regression was then applied to quantify the impact of the decapping force and patient characteristics on the perceived ease of decapping.

Results: The participants of the study effectively decapped all autoinjector devices irrespective of age, sex, and dexterity impairments. Moreover, the study reveals that the perceived ease of decapping decreases significantly with increasing decapping force and participants' dexterity impairments.
\end{abstract}

Conclusion: The study provides initial empirical evidence on the ability of users to decap autoinjector devices and shows how increasing the cap-removal force and dexterity impairments reduce the perceived ease of decapping.

Keywords: subcutaneous injection, drug delivery, self-injection, autoinjector-cap removal, user-centric device development

\section{Introduction}

Soaring interest in biologics and their subcutaneous delivery has accelerated the market uptake of pre-filled autoinjectors for the automated self-administration of single fixed doses across chronic disease states. ${ }^{1,2}$ While such autoinjectors typically maintain the pharmacokinetics, efficacy, and safety profiles of manual injections, ${ }^{3,4}$ they offer distinct advantages over syringes that shape patient preference and adherence. First, pre-filled autoinjectors are preferred over syringes in head-to-head comparison studies, thus influencing overall treatment choices. ${ }^{5}$ Second, patients find autoinjectors highly convenient and easy to use and report little to no discomfort that may prevent self-injection of future doses using autoinjectors. $^{6,7}$ Third, self-administration of biologics with an autoinjector is associated with less pain than with a syringe. ${ }^{8}$
Correspondence: Jakob Lange Ypsomed AG, Brunnmattstrasse 6, Burgdorf 340I, Switzerland Tel +4l 344243187

Email jakob.lange@ypsomed.com 
Whether and how autoinjectors are safe and effective for their intended uses and conditions of use have attracted broad scholarly interest. ${ }^{9-11}$ Several studies have offered broad insights into how patients, caregivers, and healthcare professionals perform self-injection with such devices. ${ }^{3-6,11-13}$ However, a detailed understanding of the user perception of clinically relevant technical attributes as basis for the user-centric specification thereof is still missing. The clinically relevant design attributes of the autoinjector have not been subjected to the same level of scrutiny as the dial-and-dose injection pen, ${ }^{14-18}$ the clinically-relevant technical attributes of which have been studied both in terms of human factors ${ }^{19-21}$ and competitive positioning. ${ }^{22-28}$ Therefore, Dou et $\mathrm{al}^{29}$ who recently characterized two spring-actuated autoinjectors, concluded that more research was needed to understand how clinically relevant technical attributes affect user perceptions.

The ability of users to decap the autoinjector, which in turn removes the sterility barrier of the pre-filled syringe and prepares it for the actual drug delivery, is critical for effective use of the device. Scholars often do not consider the effect of user characteristics on the perceptions of this handling step. In fact, research on human factors to date has largely focused on the performance of the subsequent handling steps. ${ }^{11,30}$ This dearth of studies is problematic for three reasons. First, the removal of the autoinjector cap is a necessary step for the safe and effective performance of self-injection. Prior works have consistently shown that autoinjector-cap removal was linked with use errors or difficulties. For example, the validation study of an autoinjector designed to deliver once-weekly exenatide suspension assigned the lowest score of all user tasks to needle cap removal. ${ }^{31}$ Another study found that the usage errors of a glucagon autoinjector were related not only to injecting through clothing but also to the failure to decap the device. ${ }^{32}$ Second, the technical characterization of the elastomer-glass interface has long been used for specifying the forces related to the pre-filled syringe sterility barrier and needle exposure. ${ }^{33}$ However, the US Food and Drug Administration (FDA) now investigates manufacturers about user-centric design principles in the design and development of new drug delivery devices and recommends specifications based on rigorous usability research rather than technical properties of device components. ${ }^{34}$ Third, autoinjector-based treatment options alleviate chronic debilitating conditions associated with cognitive and motor impairments, such as multiple sclerosis, psoriasis, and rheumatoid arthritis. ${ }^{3-5,8,9,35,36}$ Consequently, disease-specific limitations and situational factors must be carefully considered when specifying the device's technical attributes. The specification of clinically relevant attributes may not only limit the safety and efficacy of the autoinjector for the intended uses and use conditions, but also affect the device perceptions that in turn shape device preferences.

Therefore, as basis to specifying new drug delivery devices, researchers must obtain empirical evidence on the perception of target user groups about the clinically relevant technical attributes of autoinjectors. This article attempts to fill this gap between existing autoinjector design practices and the demand for user-centric devices with a non-interventional observational study based on 42 participants including patients, caregivers, and healthcare professionals. Empirical data were collected on the ability of participants to remove the autoinjector cap with different pull-off forces and their self-reported ease of decapping. The results are then used to determine whether and how participants with a range of disabilities were able to effectively decap autoinjectors with cap-removal forces of up to $55 \mathrm{~N}$. Furthermore, the data are analyzed to relate the cap-removal forces as well as patient characteristics to the self-reported perceived ease of decapping, examining whether and how age, sex, and dexterity impairments of the users influence the perceived ease of decapping.

\section{Patients and Methods}

Data were collected through a single-site, noninterventional observational study in compliance with the European Pharmaceutical Market Research Association Code of Conduct ${ }^{37}$ and the User Experience Professionals Association Code of Professional Conduct. ${ }^{38}$ No ethics committee approval was required as participants manipulated non-functional mock-up devices, and thus were not exposed to risks associated with accidental medication administration at any point in time during the study. The study was conducted in May 2018.

\section{Participants}

Participants across five user groups (G1 - G5, N = 42) were included to account for the broad user population of the autoinjector platform at hand. ${ }^{1,2,39}$ Patient users were placed in one of three age groups (adolescent patients, G1, $\mathrm{n}=6$; adult patients, $\mathrm{G} 2, \mathrm{n}=11$; elder patients, $\mathrm{G} 3, \mathrm{n}=12$ ) to assess the influence of decreasing dexterity on the ability to effectively remove the autoinjector cap. This study refers to dexterity impairment as the extent to which chronic 
rheumatoid affection of the hand influences its functional status, stiffness and pain in patients, ${ }^{40}$ an aspect that may be relevant for effective cap removal. Non-professional caregivers $(\mathrm{G} 4, \mathrm{n}=6)$ and healthcare professionals $(\mathrm{G} 5, \mathrm{n}=7)$ were included to gauge the influence of professional education and use context on assessing the cap-removal process. The participants recruited to the patient user groups (G1 G3) were diagnosed with at least one of the following chronic diseases, for which repeated subcutaneously administrated treatment options using autoinjectors exist: rheumatoid arthritis, psoriasis, psoriatic arthritis, Parkinson's disease, multiple sclerosis, asthma/chronic obstructive pulmonary disease, diabetes, osteoarthritis, and osteoporosis. The study sample, which was acquired from the Greater Philadelphia Metropolitan Area, PA, US, consisted of 28 female and 14 male participants. Both injection-naïve (15) and injection-experienced (27) subjects were recruited. Table 1 summarizes the demographics of the study participants.

\section{Study Protocol and Procedure}

The experiments were conducted in an office environment where the moderator instructed each participant according to a predefined protocol. Prior to data collection on cap removal, the participants were familiarized with the autoinjector device during a simulated use session. The participants were asked to sign a consent form and fill out a questionnaire to verify their assignment to one of the five participant groups. The questionnaire also included a standard selfreporting instrument for dexterity impairments. ${ }^{40}$ The subjects were then asked to remove the cap of four nonfunctional autoinjectors with different target cap-removal forces, which were presented in the counterbalanced order. The primary outcome measure was the effective completion of cap removal, as observed by the moderator and recorded as a binary variable. The secondary outcome measure was the user-reported perceived ease of decapping. For each handling step of cap removal, the participants reported the perceived ease of decapping using a 5-point Likert scale, with the two extreme ends being "very difficult" (1) and "very easy" (5) to remove the autoinjector protective cap.

\section{Materials}

Four non-functional mock-up autoinjector devices were designed to simulate cap removal with target forces of 25 $\mathrm{N}\left(\right.$ device $\left.F_{T 25}\right), 35 \mathrm{~N}$ (device $\left.F_{T 35}\right), 45 \mathrm{~N}\left(\right.$ device $\left.F_{T 45}\right)$, and

Table I User Population in the Study

\begin{tabular}{|c|c|c|c|c|c|}
\hline Demographics & $\begin{array}{l}\text { GI. Adolescent } \\
\text { Patients }(n=6)\end{array}$ & $\begin{array}{l}\text { G2. Adult } \\
\text { Patients } \\
(\mathrm{n}=\mathrm{II})\end{array}$ & $\begin{array}{l}\text { G3. Elderly } \\
\text { Patients } \\
(n=12)\end{array}$ & $\begin{array}{l}\text { G4. } \\
\text { Caregivers } \\
(n=6)\end{array}$ & $\begin{array}{l}\text { G5. Healthcare } \\
\text { Professionals } \\
(n=7)\end{array}$ \\
\hline Age group & $16-18$ & $34-58$ & $62-77$ & $25-63$ & $27-57$ \\
\hline \multicolumn{6}{|l|}{ Sex } \\
\hline Female & 5 & 7 & 5 & 5 & 6 \\
\hline Male & I & 4 & 7 & 1 & I \\
\hline \multicolumn{6}{|l|}{ Handedness } \\
\hline Right & 3 & 11 & 11 & 6 & 6 \\
\hline Left & 3 & 0 & 1 & 0 & 0 \\
\hline Ambidextrous & 0 & 0 & 0 & 0 & 1 \\
\hline \multicolumn{6}{|l|}{ Injection experience } \\
\hline Yes (untrained) & 3 & 9 & 6 & 2 & 7 \\
\hline No (trained) & 3 & 2 & 6 & 4 & 0 \\
\hline \multicolumn{6}{|l|}{ Impairments* } \\
\hline Vision Impairment (Corrected) & 4 & 4 & 11 & 3 & 3 \\
\hline Vision Impairment (Uncorrected) & 0 & I & 2 & 0 & \\
\hline Color-blind & 0 & I & 0 & 0 & 0 \\
\hline Neuropathy & 0 & 3 & 3 & 0 & 0 \\
\hline Fatigue & 0 & 0 & 1 & 0 & 0 \\
\hline Hearing loss & 0 & 0 & 3 & 0 & 0 \\
\hline
\end{tabular}

Note: *Some patients suffered from more than one impairment.

Abbreviation: G, group. 


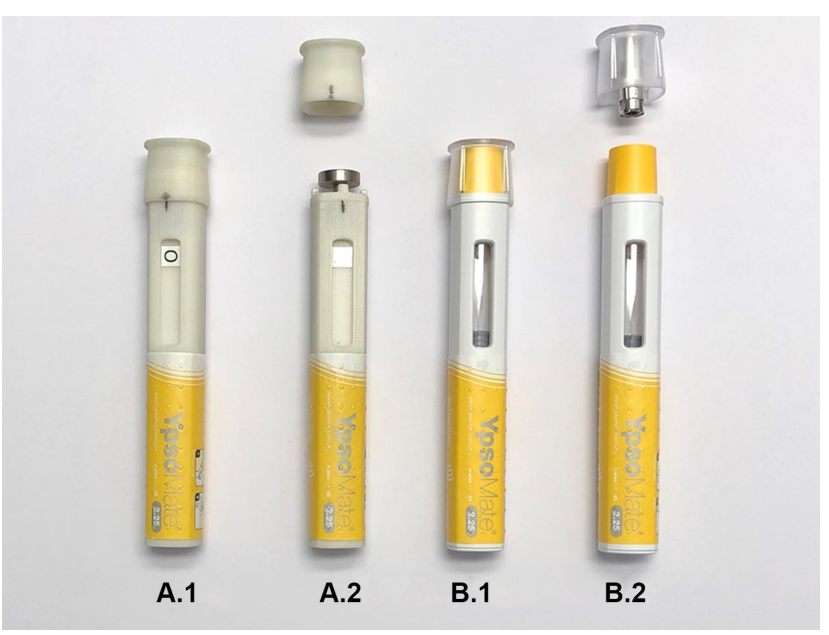

Figure I Non-functional mock-up autoinjector device used to simulate decapping handling step before (A.I) and after cap removal (A.2), and fully functional prefilled autoinjector device before (B.I) and after cap removal (B.2).

$55 \mathrm{~N}$ (device $F_{T 55}$ ). The shape and size of the mock-up devices were akin to the actual autoinjector platform device described earlier (Figure 1). 2,11,39,41 A ferromagnetic target in the cap and a permanent magnet in the device body separated by a variable air gap were used to achieve the different target cap-removal forces. Adjusting the air gap between the target and the permanent magnet with a leadscrew mechanism in the body enabled adjustment of the target cap-removal forces. The cap-removal forces were experimentally verified using a Zwick Roell Z 2.5 universal test machine (Zwick GmbH, Ulm, Germany). The results of the measurements are presented in Table 2 .

\section{Statistical Analysis}

Descriptive and inferential statistics were performed using the statistical software package STATA ver 12 (StataCorp, College Station, TX, USA). Linear regression (pooled Ordinary Least Squares OLS method) was conducted to assess the impact of the cap-removal force and characteristics of the participants on the user-reported perceived ease of decapping. The pooled

Table 2 Target and Actual Cap-Removal Force for NonFunctional Autoinjector Devices in This Study

\begin{tabular}{|l|l|l|}
\hline $\begin{array}{l}\text { Non-Functional } \\
\text { Autoinjector } \\
\text { Device }\end{array}$ & $\begin{array}{l}\text { Target Cap- } \\
\text { Removal } \\
\text { Force [N] }\end{array}$ & $\begin{array}{l}\text { Mean (SD) Actual Cap- } \\
\text { Removal Force [N] (n = } \\
\text { 20) }\end{array}$ \\
\hline $\mathrm{F}_{\mathrm{T} 25}$ & 25 & $24.7 \mathrm{I}(0.44)$ \\
$\mathrm{F}_{\mathrm{T} 35}$ & 35 & $35.79(0.99)$ \\
$\mathrm{F}_{\mathrm{T} 45}$ & 45 & $47.04(\mathrm{I} .19)$ \\
$\mathrm{F}_{\mathrm{T} 55}$ & 55 & $56.09(\mathrm{I} .8 \mathrm{I})$ \\
\hline
\end{tabular}

Abbreviation: SD, standard deviation.
OLS method was used as the Hausman test did not show any participant-specific effects of the response variable (perceived ease of decapping). Dexterity impairments, sex, and age were included as control variables. First, dexterity impairment may shape device preferences ${ }^{42}$ and is associated with inflammatory diseases, several of which offer autoinjector-based treatment options. ${ }^{7,8,43,44}$ Second, sex accounted for differences in grip strength between female and male participants. ${ }^{45}$ Third, age included as prior research showed grip strength to decrease with age. ${ }^{46}$ The explanatory variables were introduced stepwise to verify the robustness of the final regression model.

\section{Results}

All participants were able to effectively remove the autoinjector cap with various target removal forces as presented in Table 3. The impairment of the user (e.g., dexterity) did not influence the ability to effectively remove the cap. Even participants with severe dexterity impairments were able to decap the autoinjector with target cap-removal forces of up to $55 \mathrm{~N}$. No differences between patient groups in terms of injection experience, sex, age, or professional education were observed. Despite the successful task completion, difficulties were noted during the experiments. Some participants - regardless of the user group-visibly struggled with decapping the autoinjectors with higher target cap-removal forces and proactively pointed out the difficulties of usage during the study.

Data on the perceived ease of decapping were collected using self-reported questionnaires. Figure 2 illustrates the perceived ease of decapping per device type. Descriptive analysis shows that the perceived ease of decapping steadily decreased with higher cap-removal force. The participants identified the cap with a target force of $25 \mathrm{~N}$ as the easiest to remove and that with $55 \mathrm{~N}$ as the most difficult. In fact, the mean values for participant-reported perceived ease of decapping using the 5-point Likert scale decreased from 4.62 (SD: 0.54) to 3.79 (SD: 1.09), 3.19 (SD: 1.13), and 2.69 (SD: 1.09) when the target force increased from $25 \mathrm{~N}$ to $35 \mathrm{~N}, 45 \mathrm{~N}$, and $55 \mathrm{~N}$, respectively.

The observation that the perceived ease of decapping decreases with increasing pull-off force was also reflected within each user group. Table 3 details the descriptive statistics for the participant-reported perceived ease of decapping per user group. The healthcare professionals gave the highest ratings to the ease of decapping for all devices. While adult and elder patients gave the most critical feedback about the perceived ease of decapping for the two devices with the lowest decapping target forces (device $F_{T 25}$ and device $F_{T 35}$ ), 
Table 3 Participant Ability to Decap Autoinjector Devices (A) and User-Reported Perceived Ease of Decapping Measured Using a 5-Point Likert Scale (B) per User Group and Device Type $\left(\mathrm{F}_{\mathrm{T} 25}-\mathrm{F}_{\mathrm{T} 55}\right)$

\begin{tabular}{|c|c|c|c|c|}
\hline \multirow{2}{*}{ Device $\mathbf{F}_{\mathbf{T} 25}$} & \multirow{2}{*}{$\begin{array}{l}\text { A. Ability to Decap } \\
\text { Decapping Success Rate in [\%] }\end{array}$} & \multicolumn{3}{|c|}{ B. Perceived Ease of Decapping } \\
\hline & & Mean (SD) & Median & Minimum/Maximum \\
\hline GI: Adolescent patients & $100 \%$ & $4.67(0.5 \mathrm{I})$ & 5.0 & $4 / 5$ \\
\hline G2: Adult patients & $100 \%$ & $4.55(0.69)$ & 5.0 & $3 / 5$ \\
\hline G3: Elder patients & $100 \%$ & $4.58(0.5 \mathrm{I})$ & 5.0 & $4 / 5$ \\
\hline G4: Non-professional caregivers & $100 \%$ & $4.67(0.52)$ & 5.0 & $4 / 5$ \\
\hline G5: Healthcare professionals & $100 \%$ & $4.71(0.49)$ & 5.0 & $4 / 5$ \\
\hline Total (G I-G5) n=42 & $100 \%$ & $4.62(0.54)$ & 5.0 & $3 / 5$ \\
\hline Device $\mathbf{F}_{\mathrm{T} 35}$ & Decapping Success Rate in [\%] & Mean (SD) & Median & Minimum/Maximum \\
\hline GI: Adolescent patients & $100 \%$ & $3.50(1.05)$ & 3.50 & $2 / 5$ \\
\hline G2: Adult patients & $100 \%$ & $3.82(1.40)$ & 4.0 & $1 / 5$ \\
\hline G3: Elder patients & $100 \%$ & $3.75(1.14)$ & 4.0 & $2 / 5$ \\
\hline G4: Non-professional caregivers & $100 \%$ & $4.00(1.10)$ & 4.0 & $2 / 5$ \\
\hline G5: Healthcare professionals & $100 \%$ & $3.86(0.69)$ & 4.0 & $3 / 5$ \\
\hline Total (GI-G5) n=42 & $100 \%$ & $3.79(1.09)$ & 4.0 & $1 / 5$ \\
\hline Device $\mathbf{F}_{\mathrm{T45}}$ & Decapping Success Rate in [\%] & Mean (SD) & Median & Minimum/Maximum \\
\hline GI: Adolescent patients & $100 \%$ & $3.17(1.17)$ & 3.0 & $2 / 5$ \\
\hline G2: Adult patients & $100 \%$ & $3.09(1.45)$ & 3.0 & $1 / 5$ \\
\hline G3: Elder patients & $100 \%$ & $3.25(0.87)$ & 3.0 & $2 / 5$ \\
\hline G4: Non-professional caregivers & $100 \%$ & $2.50(1.22)$ & 2.0 & $1 / 4$ \\
\hline G5: Healthcare professionals & $100 \%$ & $3.86(0.69)$ & 4.0 & $3 / 5$ \\
\hline Total (GI-G5) n=42 & $100 \%$ & $3.19(1.13)$ & 3.0 & $1 / 5$ \\
\hline Device $\mathbf{F}_{\mathrm{T} 55}$ & Decapping Success Rate in [\%] & Mean (SD) & Median & Minimum/Maximum \\
\hline GI: Adolescent patients & $100 \%$ & $2.33(1.03)$ & 2.0 & $1 / 4$ \\
\hline G2: Adult patients & $100 \%$ & $2.36(1.21)$ & 2.0 & $1 / 4$ \\
\hline G3: Elder patients & $100 \%$ & $2.83(1.19)$ & 2.5 & $1 / 5$ \\
\hline G4: Non-professional caregivers & $100 \%$ & $2.33(0.82)$ & 2.0 & $2 / 4$ \\
\hline G5: Healthcare professionals & $100 \%$ & $3.57(0.53)$ & 4.0 & $3 / 4$ \\
\hline Total (GI-G5) n=42 & $100 \%$ & $2.69(1.09)$ & 2.0 & $1 / 5$ \\
\hline
\end{tabular}

Abbreviation: SD, standard deviation.

the non-professional caregivers gave the lowest rating for the two devices with the highest decapping target forces (device $F_{T 45}$ and device $F_{T 55}$ ).

The effects of the device decapping force and patient characteristics on the perceived ease of decapping were then quantified using linear regression analysis (pooled OLS model). Table 4 lists the linear regression model estimates and related standard errors. The model exhibits a significant negative effect of cap-removal force on the perceived ease of decapping (coefficient, $-0.064 ; p<$ 0.001 ). Moreover, the results suggest a significant negative effect of dexterity impairment on the perceived ease of decapping (coefficient, $-0.075 ; p<0.05$ ). Sex and age did not have any significant impact on the perceived ease of decapping. Figure 3 presents the linear regression model results, including the $95 \%$ confidence interval, for the perceived ease of decapping against the decapping force. Figure 3 also compares the negative effects of cap-removal force on perceived ease of decapping for participants without dexterity impairment with participants with severe dexterity impairment based on M-SACRAH. ${ }^{40}$

\section{Discussion}

The ability of users to safely and effectively perform selfinjections using pre-filled syringe-based autoinjectors has been extensively investigated in previous work. ${ }^{30-32,39,47}$ 


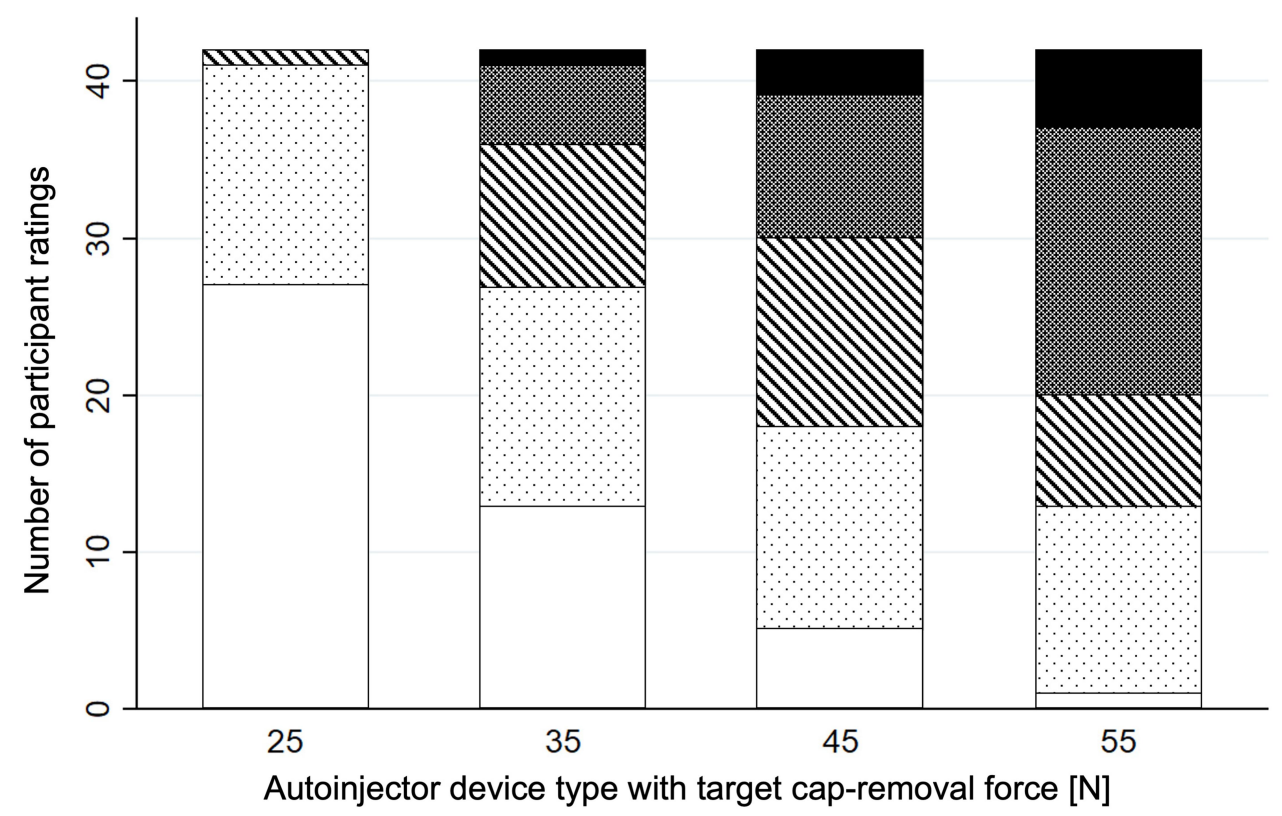

Participant-rated perceived ease of decapping
$\begin{array}{lll}\square \text { Very easy } & \because \text { Easy } \\ \text { Difficult } & \square \text { Very difficult }\end{array}$

Figure 2 Participant-rated perceived ease of decapping using a 5-point Likert scale per autoinjector device type with target autoinjector-cap removal forces between 25 $\mathrm{N}$ and $55 \mathrm{~N}$.

However, researchers have only recently begun to study the clinically relevant technical characteristics of springactuated autoinjectors and their impact on patient perceptions about the ease of handling them. ${ }^{29}$ In particular, the

Table 4 Summary Statistics for the Linear Regression Model Considering Ease of Decapping as Response Variable

\begin{tabular}{|c|c|c|}
\hline & \multicolumn{2}{|c|}{$\begin{array}{l}\text { Response } \\
\text { Variable: Ease of } \\
\text { Decapping }\end{array}$} \\
\hline & Coeff. & S.E. \\
\hline \multicolumn{3}{|l|}{ Explanatory variable } \\
\hline Cap-removal force & $-0.064^{* *}$ & $(0.006)$ \\
\hline \multicolumn{3}{|l|}{ Control variables } \\
\hline Dexterity impairments (M- SACRAH score ${ }^{40}$ ) & $-0.075^{*}$ & $(0.036)$ \\
\hline Age & 0.006 & $(0.004)$ \\
\hline Sex & 0.171 & $(0.178)$ \\
\hline Intercept & $5.944 * *$ & $(0.288)$ \\
\hline Number of observations & \multicolumn{2}{|l|}{168} \\
\hline$F(4,163)$ & \multicolumn{2}{|l|}{$31.10 * *$} \\
\hline$R^{2}$ & \multicolumn{2}{|l|}{0.372} \\
\hline
\end{tabular}

Notes: ${ }^{*} p<0.05 ;{ }^{* *} p<0.001$

Abbreviations: Coeff., coefficient; SE, standard error (robust). ability of users to remove the protective caps on autoinjectors and initiate self-injection has not been explored. This work provides initial empirical evidence on user perceptions and their ability to decap autoinjector devices. The article also describes whether and how dexterity impairments, age, and sex influence their perception of the cap removal force of autoinjectors. The study makes three important contributions to the literature on device development and human factors. First, the study shows that all participants of the study effectively decap all autoinjector devices with cap-removal forces of up to 55 $\mathrm{N}$, irrespective of sex, age, dexterity impairment, or past injection experience. Second, the study quantifies the extent to which an increase in decapping force resulted in lower participant-reported perceived ease of de-capping. Third, the study finds that dexterity impairments negatively impact the self-reported ease of decapping.

The findings that all participants were able to remove all caps contributes to our understanding of the upper limits of the cap-removal force that may prevent effective device usage. Whereas previous research suggested cap removal as a critical handling step associated with usage errors, ${ }^{31,32}$ the results show that the cap-removal forces of up to $55 \mathrm{~N}$ still enable effective device usage. These 

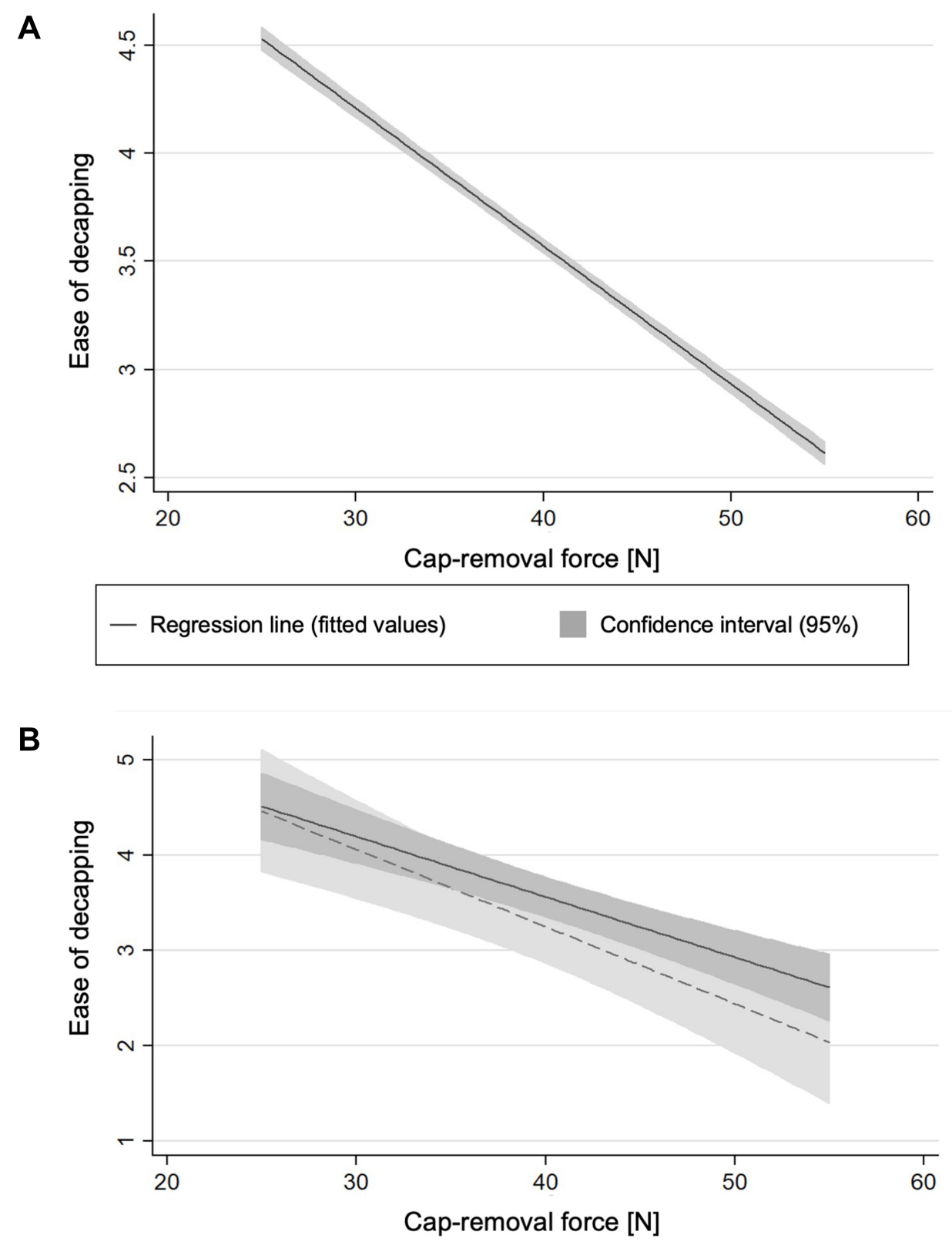

\begin{tabular}{|ll|}
\hline $\begin{array}{l}\text { Regression line (fitted values) } \\
\text { Without dexterity impairment }\end{array}$ & $\begin{array}{l}\text { Confidence interval (95\%) } \\
\text { Without dexterity impairment }\end{array}$ \\
$\begin{array}{l}\text { Regression line (fitted values) } \\
\text { Severe dexterity impairment }\end{array}$ & $\begin{array}{l}\text { Confidence interval (95\%) } \\
\text { Severe dexterity impairment }\end{array}$ \\
\hline
\end{tabular}

Figure 3 Estimated linear relation (pooled OLS model) between autoinjector-cap removal force and perceived ease of decapping for all participants (A) and for participants with severe dexterity impairment (M-SACRAH $\geq 5.0$ ) and for participants without dexterity impairments $(M-S A C R A H=0.0)(B)$

results are in line with prior anthropometric research on the finger pull strength. In an experimental setting with male healthy volunteers, Imrhan et al observed user forces of up to $98 \mathrm{~N}$ when pulling with one hand on a force sensor held by the other hand. ${ }^{48}$ Their research also pointed out the need for an ergonomic design to accommodate the different types of pinch grips, such as the chuck pinch grip, which has been shown to generate higher pull forces compared to the chuck pinch pull or the pulp punch grip. This study contains a similar piece of observational evidence, which states that when participants noted difficulties in removing the cap with higher 
target decapping forces, they used different pinch grips to decap the autoinjectors (data not shown). Thus, the study underscores how device geometry can influence effective decapping and highlights the need for a flexible industrial design to allow for different pinch grips during device handling.

The result that increasing cap-removal force results in lower participant-reported perceived ease of decapping has implications for the specification of new devices. The linear regression model suggests that an increase in the decapping force by $1 \mathrm{~N}$ reduces the user-reported perceived ease of decapping by 0.064 points on the 5 -point Likert scale. Understanding the effects of a clinically relevant device technical attribute on participant perception holds great promise for the future design of autoinjector devices. In fact, the observed reduction in the perceived ease of decapping by an increase in the decapping force justifies a quantitative user-centric approach to specifying the device's technical attributes. For instance, starting from the mean value of 4.62 for the user-reported perceived ease of decapping with a cap-removal force of 25 $\mathrm{N}$ (see Table 3), the specification of this force may be increased by $9 \mathrm{~N}$ while maintaining a target ease of decapping value of 4.0 using the 5-point Likert scale. These insights enable a more informed device development and user-centric approach to specifying clinically relevant device technical attributes. Even if scholars have long debated patient preference and ease of use of drug delivery devices, ${ }^{24,49-51}$ they have not discussed the preferences of a user for specific device technical attributes.

The findings that participants' level of dexterity impairment affects the user-reported ease of decapping suggest that dexterity impairment negatively influences user perceptions of the handling step and therefore shapes overall device preferences. The linear regression model uncovers a significant negative effect of dexterity impairment on the perceived ease of decapping (Figure 3). Patients with a higher score on the scale used to quantify the chronic rheumatoid affection of the hands reported unease during decapping the autoinjector compared with patients with no restricted function and activities of the hand. Figure 3 illustrates this effect by showing a steeper regression line and thus a stronger decrease in perceived ease of decapping for participants with severe dexterity impairments. These findings hold important implications for the design of autoinjector devices used to treat chronic debilitating disease states, such as rheumatoid arthritis, psoriasis, or multiple sclerosis. Practitioners should consider the device decapping force as the key design challenge as it may well shape device perceptions and preferences in comparative assessments. This is particularly critical, since manufacturers need to differentiate their offerings against strong in-class competition in the target disease states, such as psoriasis $^{52,53}$ or rheumatoid arthritis. $5,8,9,12,43$

Despite the study's contributions to the existing literature, several limitations merit discussion. First, the results are based on a non-randomized and exploratory observational study with limited sample size. Second, the geometry, gripping surface and texture were identical for all study devices. Third, the grip type and strength employed by the participants when performing the de-capping task were neither controlled nor monitored.

Given these limitations, future studies should corroborate the results using a broader sample and more diverse user groups. Assessing the decapping force for devices with different form factors will also deepen the understanding of the relationship of decapping force and its impact on user perceptions with the device geometry, gripping surface or textures to optimize acceptability, ease of decapping, and device preference. Moreover, future work should provide a more nuanced understanding of user behavior and the pinch grip used to decap the autoinjector device. In particular, the way the pinch grip informs the device design, and consequently the pull strength, could be of great importance for the usercentric design of future autoinjector devices. Future works should also study holistically the user perceptions of various technical attributes of the device, such as the force profile while inserting the needle or the grip strength required to keep the autoinjector pushed on skin.

\section{Conclusion}

The study explored the ability of users to remove the protective cap of autoinjector devices and assessed the impact of the device cap-removal force and user characteristics on the user-rated perceived ease of decapping, an aspect largely overlooked by previous research. On the one hand, the study shows that user characteristics such as age, dexterity impairment, or device experience did not influence their ability to remove the autoinjector cap with a target decapping force of up to $55 \mathrm{~N}$. On the other hand, the cap-removal force and dexterity impairment did negatively influence the user-rated perceived ease of decapping, which ultimately may shape device preferences. Thus, the study underscores the necessity of considering human factor-induced perspectives on the characterization 
of the device's technical attributes, such as the required force to remove the autoinjector protective cap.

\section{Acknowledgments}

The authors thank the participants in this study. The study was financed by Ypsomed AG and conducted by Design Science.

\section{Disclosure}

AS, PR, PM, CJ and JL are employees for Ypsomed AG. MY is an employee of Design Science. The authors report no other conflicts of interest in this work.

\section{References}

1. Schneider A, Kolrep H, Jordi C, et al. How to prevent medication errors: a multidimensional scaling study to investigate the distinguishability between self-injection platform device variants. Expert Opin Drug Deliv. 2019;16(8):883-894. doi:10.1080/17425247.20 19.1637852

2. Lange J, Richard P, Bradley N. Usability of a new disposable autoinjector platform device: results of a formative study conducted with a broad user population. Med Devices (Auckl). 2015;8:255-264. doi:10.2147/MDER.S85938

3. Kivitz A, Baret-Cormel L, van Hoogstraten H, et al. Usability and patient preference phase 3 study of the sarilumab pen in patients with active moderate-to-severe rheumatoid arthritis. Rheumatol Ther 2018;5(1):231-242. doi:10.1007/s40744-017-0090-2

4. Callis Duffin K, Bagel J, Bukhalo M, et al. Phase 3, open-label, randomized study of the pharmacokinetics, efficacy and safety of ixekizumab following subcutaneous administration using a prefilled syringe or an autoinjector in patients with moderate-to-severe plaque psoriasis (UNCOVER-A). J Eur Acad Dermatol Venereol. 2017;31 (1):107-113. doi:10.1111/jdv.13768

5. Rho YH, Rychlewska-Hańczewska A, Śliwowska B, et al. Usability of prefilled syringe and autoinjector for SB4 (an etanercept biosimilar) in patients with rheumatoid arthritis. Adv Ther. 2019;36 (9):2287-2295. doi:10.1007/s12325-019-01027-z

6. Dashiell-Aje E, Harding G, Pascoe K, et al. Patient evaluation of satisfaction and outcomes with an autoinjector for self-administration of subcutaneous belimumab in patients with systemic lupus erythematosus. Patient. 2018;11(1):119-129. doi:10.1007/s40271017-0276-2

7. Vermeire S, D'heygere F, Nakad A, et al. Preference for a prefilled syringe or an auto-injection device for delivering golimumab in patients with moderate-to-severe ulcerative colitis: a randomized crossover study. Patient Prefer Adherence. 2018;12:1193-1202. doi:10.2147/PPA.S154181

8. Kivitz A, Cohen S, Dowd JE, et al. Clinical assessment of pain, tolerability, and preference of an autoinjection pen versus a prefilled syringe for patient self-administration of the fully human, monoclonal antibody adalimumab: the TOUCH trial. Clin Ther. 2006;28 (10):1619-1629. doi:10.1016/j.clinthera.2006.10.006

9. Hudry C, Lebrun A, Moura B, et al. Evaluation of usability and acceptance of a new autoinjector intended for methotrexate subcutaneous self-administration in the management of rheumatoid arthritis. Rheumatol Ther. 2017;4(1):183-194. doi:10.1007/s40744017-0057-3

10. Matfin G, Van Brunt K, Zimmermann AG, et al. Safe and effective use of the once weekly dulaglutide single-dose pen in injection-naïve patients with type 2 diabetes. J Diabetes Sci Technol. 2015;9 (5):1071-1079. doi:10.1177/1932296815583059
11. Brooks CC, Martin LJ, Pilipenko V, et al. Usability of mepolizumab single-use prefilled autoinjector for patient self-administration. J Asthma. 2019;1-12. doi:10.1080/02770903.2019.1694941

12. Schiff M, Koo J, Jin E, et al. Usability and acceptability of the abatacept pre-filled autoinjector for the subcutaneous treatment of rheumatoid arthritis. Adv Ther. 2016;33(2):199-213. doi:10.1007/ s12325-016-0286-9

13. Duffin CK, Bukhalo M, Bobonich MA, et al. Usability of a novel disposable autoinjector device for ixekizumab: results from a qualitative study and an open-label clinical trial, including patient-reported experience. Med Devices (Auckl). 2016;9:361-369. doi:10.2147/MDER.S113752

14. Bode A. Development of the SoloSTAR ${ }^{\circledR}$ insulin pen device: design verification and validation. Expert Opin Drug Deliv. 2009;6 (1):103-112. doi:10.1517/17425240802636187

15. Bailey T, Campos C. FlexTouch(R) for the delivery of insulin: technical attributes and perception among patients and healthcare professionals. Expert Rev Med Devices. 2012;9(3):209-217. doi:10.1586/erd.12.13

16. Schwartz SL, Ignaut DA, Bodie JN. Humalog((R)) KwikPen: an insulin-injecting pen designed for ease of use. Expert Rev Med Devices. 2010;7(6):735-743. doi:10.1586/erd.10.63

17. Yuen KCJ, Amin R. Developments in administration of growth hormone treatment: focus on Norditropin $\left({ }^{\circledR}\right)$ Flexpro $\left({ }^{\circledR}\right)$. Patient Prefer Adherence. 2011;5:117-124. doi:10.2147/PPA.S10985

18. Mahony MC, Patterson P, Hayward B, et al. Human factors engineering and design validation for the redesigned follitropin alfa pen injection device. Expert Opin Drug Deliv. 2015;12(5):715-725. doi:10.1517/17425247.2015.1033395

19. Mahony M, Dwyer A, Barkume R, et al. US human factors engineering evaluation of an updated follitropin alfa pen injector (GONAL- ${ }^{\circledR}$ RFF redi-ject $\left.{ }^{\circledR}\right)$ and instructions for use. Expert Opin Drug Deliv. 2018;15(1):5-15. doi:10.1080/17425247.2018.1402886

20. Schwartz S, Vlajnic A. Validation of the SoloSTAR insulin pen. Diabetes Technol Ther. 2008;10(5):351-357. doi:10.1089/dia.2008. 0079

21. Lange J, Richard P, Bradley N. Usability of devices for self-injection: results of a formative study on a new disposable pen injector. Med Devices (Auckl). 2014;7:195-203. doi:10.2147/ MDER.S63918

22. Van der Burg T. Injection force of SoloSTAR(R) compared with other disposable insulin pen devices at constant volume flow rates. J Diabetes Sci Technol. 2011;5(1):150-155. doi:10.1177/193229681 100500120

23. Haak T, Edelman S, Walter C, et al. Comparison of usability and patient preference for the new disposable insulin device Solostar versus Flexpen, lilly disposable pen, and a prototype pen: an open-label study. Clin Ther. 2007;29(4):650-660. doi:10.1016/j. clinthera.2007.04.003

24. Pfutzner A, Forst T, Niemeyer M, et al. Assessment for ease of use and preference of a new prefilled insulin pen (FlexTouch degludec U100/U200) versus the SoloSTAR insulin pen by patients with diabetes and healthcare professionals. Expert Opin Drug Deliv. 2014;11 (9):1381-1389. doi:10.1517/17425247.2014.927438

25. Bohnet J, Schmitz M, Kamlot S, et al. Dosing accuracy and insulin flow rate characteristics of a new disposable insulin pen, FlexTouch, compared with SoloSTAR. J Diabetes Sci Technol. 2013;7 (4):1021-1026. doi:10.1177/193229681300700426

26. Ignaut DA, Opincar M, Lenox S. FlexPen ${ }^{\circledR}$ and KwikPen ${ }^{\mathrm{TM}}$ prefilled insulin devices: a laboratory evaluation of ergonomic and injection force characteristics. J Diabetes Sci Technol. 2008;2(3):533-537. doi: $10.1177 / 193229680800200327$

27. Schneider AE, Lange J. Pen devices for self-injection: contrasting measured injection force with users' perceived ease of injection. Expert Opin Drug Deliv. 2018;15(2):115-125. doi:10.1080/17425 247.2018.1415884 
28. Wang T, Conrad KA, van Brunt K, et al. Attributes influencing insulin pen preference among caregivers and patients with diabetes who require greater than 20 units of mealtime insulin. J Diabetes Sci Technol. 2016;10(4):923-931. doi:10.1177/1932296816633232

29. Dou Z, Eshraghi J, Guo T, et al. Performance characterization of spring actuated autoinjector devices for Emgality and Aimovig. Current Med Res Opin. 2020;36(8):1-12.

30. Schwarzenbach F, Dao Trong M, Grange L, et al. Results of a human factors experiment of the usability and patient acceptance of a new autoinjector in patients with rheumatoid arthritis. Patient Prefer Adherence. 2014;8:199. doi:10.2147/PPA.S50583

31. LaRue S, Springer J, Noderer M, et al. Evaluation of the use of exenatide once-weekly suspension autoinjector among patients with type 2 diabetes mellitus and health care professionals. J Diabetes Sci Technol. 2019;13(2):226-234. doi:10.1177/1932296818798376

32. Valentine V, Newswanger B, Prestrelski S, et al. Human factors usability and validation studies of a glucagon autoinjector in a simulated severe hypoglycemia rescue situation. Diabetes Technol Ther. 2019;21(9):522-530. doi:10.1089/dia.2019.0148

33. Peláez SS, Mahler H-C, Matter A, et al. Container closure integrity testing of prefilled syringes. J Pharm Sci. 2018;107(8):2091-2097. doi:10.1016/j.xphs.2018.03.025

34. US Food and Drug Administration. Applying Human Factors and Usability Engineering to Medical Devices. Guidance for Industry and Food and Drug Administration staff; 2016.

35. Hupperts R, Becker V, Friedrich J, et al. Multiple sclerosis patients treated with intramuscular IFN- $\beta$-1a autoinjector in a real-world setting: prospective evaluation of treatment persistence, adherence, quality of life and satisfaction. Expert Opin Drug Deliv. 2015;12 (1):15-25. doi:10.1517/17425247.2015.989209

36. Seddighzadeh A, Hung S, Selmaj K, et al. Single-use autoinjector for peginterferon- $\beta$ 1a treatment of relapsing-remitting multiple sclerosis: safety, tolerability and patient evaluation data from the phase IIIb ATTAIN study. Expert Opin Drug Deliv. 2014;11(11):1713-1720. doi:10.1517/17425247.2014.944159

37. EPMR Association. EphMRA 2017 Code of Conduct V4.indd. European Pharmaceutical Market Research Association; 2017.

38. UP Association. UPA Code of Professional Conduct for Usability Practitioners. Usability Professionals' Association; 2005.

39. Schneider A, Mueller P, Jordi C, et al. Hold the device against the skin: the impact of injection duration on user's force for handheld autoinjectors. Expert Opin Drug Deliv. 2020;17(2):225-236. doi:10.1080/17425247.2020.1704730

40. Sautner J, Andel I, Rintelen B, Leeb BF. Development of the M-SACRAH, a modified, shortened version of SACRAH (Score for the Assessment and Quantification of Chronic Rheumatoid Affections of the Hands). Rheumatology. 2004;43(11):1409-1413. doi:10.1093/rheumatology/keh360
41. Xiao X, Li W, Clawson C, et al. Evaluation of performance, acceptance, and compliance of an auto-injector in healthy and rheumatoid arthritic subjects measured by a motion capture system. Patient Prefer Adherence. 2018;12:515-526. doi:10.2147/PPA.S160394

42. Pfutzner A, Schipper C, Niemeyer M, et al. Comparison of patient preference for two insulin injection pen devices in relation to patient dexterity skills. J Diabetes Sci Technol. 2012;6(4):910-916. doi:10. 1177/193229681200600423

43. Domanska B, VanLunen B, Peterson L, et al. Comparative usability study for a certolizumab pegol autoinjection device in patients with rheumatoid arthritis. Expert Opin Drug Deliv. 2017;14(1):15-22. doi:10.1080/17425247.2016.1256283

44. Thakur K, Biberger A, Handrich A, et al. Patient perceptions and preferences of two etanercept autoinjectors for rheumatoid arthritis: findings from a patient survey in Europe. Rheumatol Ther. 2016;3 (2):245-256. doi:10.1007/s40744-016-0048-9

45. Haward BM, Griffin MJ. Repeatability of grip strength and dexterity tests and the effects of age and gender. Int Arch Occup Environ Health. 2002;75(1-2):111-119. doi:10.1007/s004200100285

46. Martin JA, Ramsay J, Hughes C, et al. Age and grip strength predict hand dexterity in adults. PLoS One. 2015;10(2):e0117598. doi:10.13 71/journal.pone.0117598

47. Phillips JT, Fox E, Grainger W, et al. An open-label, multicenter study to evaluate the safe and effective use of the single-use autoinjector with an avonex ${ }^{\circledR}$ prefilled syringe in multiple sclerosis subjects. BMC Neurol. 2011;11(1):126. doi:10.1186/1471-2377-11-126

48. Imrhan SN, Sundararajan K. An investigation of finger pull strengths. Ergonomics. 1992;35(3):289-299. doi:10.1080/00140139208967814

49. Andre AD, Brand-Schieber E, Ramirez M, et al. Subcutaneous sumatriptan delivery devices: comparative ease of use and preference among migraineurs. Patient Prefer Adherence. 2017;11:121-129. doi:10.2147/PPA.S125137

50. Egeth M, Soosaar J, Nash P, et al. Patient and healthcare professionals preference for Brenzys vs. Enbrel autoinjector for rheumatoid arthritis: a randomized crossover simulated-use study. Adv Ther. 2017;34(5):1157-1172. doi:10.1007/s12325-017-0523-x

51. Di Cantogno VE, Tomlinson M, Manuel L, et al. Autoinjector preference in multiple sclerosis and the role of nurses in treatment decisions: results from an international survey in Europe and the USA. Pragmat Obs Res. 2014;5:53-64. doi:10.2147/POR.S72012

52. Blauvelt A, Prinz JC, Gottlieb AB, et al. Secukinumab administration by pre-filled syringe: efficacy, safety and usability results from a randomized controlled trial in psoriasis (FEATURE). $\mathrm{Br}$ $J$ Dermatol. 2015;172(2):484-493. doi:10.1111/bjd.13348

53. Paul C, Stalder JF, Thaçi D, et al. Patient satisfaction with injection devices: a randomized controlled study comparing two different etanercept delivery systems in moderate to severe psoriasis. J Eur Acad Dermatol Venereol. 2012;26(4):448-455. doi:10.1111/j.14683083.2011.04093.x
Patient Preference and Adherence

\section{Publish your work in this journal}

Patient Preference and Adherence is an international, peer-reviewed, open access journal that focusing on the growing importance of patient preference and adherence throughout the therapeutic continuum. Patient satisfaction, acceptability, quality of life, compliance, persistence and their role in developing new therapeutic modalities and compounds to optimize clinical outcomes for existing disease states are major areas of interest for the journal. This journal has been accepted for indexing on PubMed Central. The manuscript management system is completely online and includes a very quick and fair peer-review system, which is all easy to use. Visit http:// www.dovepress.com/testimonials.php to read real quotes from published authors. 